\title{
A GEOMORFOLOGIA, A EDAFOLOGIA E O ORDENAMENTO DO ESPAÇO RURAL*
}

\author{
JEAN TRICART
}

Vimos que a consciência dos danos experimentados pelas terras cultivadas causada pelas grandes torrentes ou pela fusão das neves é uma das origens da Geomorfologia. Desde o período dos fisiocratas, os agrônomos têm-se inclinado sobre esta questão de importância vital para a humanidade. Nas estações experimentais estabeleceram áreas de pesquisa para o estabelecimento das medidas de perdas de solo em função das diferentes culturas e das técnicas agrícolas. Porém a análise de tais condições, ainda que indispensáveis e preciosas, não é suficiente. Permite apreender só um aspecto de um vasto problema e pode comparar-se ao tubo de ensaio do fisiólogo se comparado com a escala de observações do ecólogo.

A Geomorfologia pode permitir tirar partido dessas pacientes medidas na ordenação da terra, no modelado da paisagem agrícola. O presente capítulo é dedicado a este tema e as ordenações rurais de caráter hidráulico serão apresentadas no capítulo 5.

\section{Os mecanismos da morfogênese agrícola}

Certo número de agrônomos utilizam a expressão erosão agrícola para designar esse processo. Etimologicamente, todavia, essa expressão não se pode aplicar senão a uma parte dos traumas que o deslocamento da vegetação natural pelos cultivos inflige à natureza. Com efeito, a erosão tem por corolário fenômenos de transporte $\mathrm{e}$

\footnotetext{
* Capítulo 3 de La Epidermis de la Tierra, Editorial Labor, Nueva Colección Labor, Barcelona, 1969
} 
acumulação, cujo conjunto está englobado em termos de morfogênese. Por exemplo, na Alemanha se pode demonstrar com precisão, por meio do pólen ou das descobertas arqueológicas, que camadas de lama que ocupam as planícies inundáveis, cuja espessura alcança às vezes cinco metros, se depositaram durantes crises agrícolas sucessivas primeiramente a partir dos grandes desmontes do neolítico, e depois da Idade Média. Em Londres, demonstramos que os alicerces dos moinhos galoromanos repousavam sobre uma débil camada de material de transbordamentos e estavam soterrados por baixo de mais dois metros de depósitos posteriores. Os desmontes medievais aceleraram, portanto, a acumulação dessas formações antrópicas. Certamente, uma boa parte do solo arrebatado às parcelas cultivadas é arrastada para longe, até os estuários e o mar. $\mathrm{O}$ assoreamento acelerado dos estuários da costa este dos Estados Unidos, sobretudo da baía do Chesapeake, que dificultava a navegação, é a consequência direta dos devastadores métodos de cultivo praticados naquela região há mais de cinquenta anos. Numerosas planícies aluvionais se tornam pantanosas porque o transporte crescente de lama provoca a formação, após as inundações, de levantamentos cada vez mais altos na borda dos leitos menores e que retêm a água das enchentes aprisionadas nas bacias do leito maior onde se estancam. Tal é o caso, sobretudo, de numerosos vales de vinhedos da Gasconha cujo estudo foi confiado ao Centro de Geografia Aplicada. O desenvolvimento do cultivọ do milho, que ativa a erosão agrícola, piora a situação e obriga a preparar um programa de saneamento: soterradas no inverno, estas terras férteis dão colheitas medíocres quando deveriam ser o lugar de uma agricultura intensiva, ao amparo da erosão.

É preciso, portanto, ter em conta uma idéia, muito natural entre os geomorfólogos, porém que os agrônomos geralmente esquecem: os danos provocados por uma acentuação antrópica da morfogênese se deixam sentir tanto nas zonas originárias de materiais (erosão das terras cultivadas) como nas de acumulação (coluvionamento ao pé das vertentes ou no fundo de pequenos vales, modificação do modelado das planícies aluvionais, assoreamento dos cursos d"agua e dos estuários, depósito en cones de dejeção). Os dois aspectos estão intrinsecamente vinculados por uma espécie de lei de lavoisier geomorfológica e devem ser tratados conjuntamente em uma ordenação racional das terras. Porém, nesta morfogênese antrópica, o fenômeno motor, o fenômeno original, é a erosão. Os processos de acumulação são desencadeados por ele e revestem a forma habitual na maior parte dos casos, e seus mecanismos diferem só por sua intensidade.

\section{A agricultura e o equilíbrio morfogenético}

Os mecanismos da erosão agrícola resultam de uma verdadeira ruptura do equilíbrio natural que afeta a um só tempo a cobertura vegetal e os solos.

A cobertura vegetal é substituída por outra cujas propriedades geomorfológicas são muito diferentes. Na França basta evocar a comparação entre o bosque silvestre, cheio 
de árvores, arbustos e lianas, e o campo de batatas, de beterraba ou de trigo. As plantas cultivadas nunca alcançam a mesma densidade que a vegetação natural, submetida às duras leis da concorrência biológica. Folhas e ramos constituem, aqui, uma tela de proteção menos eficaz contra o bombardeio do solo pelas gotas das chuvas (erosão pluvial). A retenção das tempestades por um bosque alcança de 23 a $30 \%$ do total anual das chuvas. Em um campo de cultivo, de 10 a $15 \%$ depois do desenvolvimento máximo das plantas. Entre as plantas cultivadas, em certas estações, o campo não está coberto por nenhuma vegetação protetora. As gotas das chuvas golpeiam diretamente a terra. Situação que no âmbito da natureza não se produz senão nas regiões secas, de cobertura vegetal descontínua, praticamente jamais acontecendo em áreas de bosque, nas quais as gotas d'água são detidas pelos ramos das árvores.

A energia cinética das gotas das chuvas é considerável. Desprende partículas do solo que são logo arrastadas pelos cursos dos rios. Para convencer-se disso não há mais que observar, depois de uma tempestade, os objetos abandonados na superfície do solo desnudo: sua parte inferior, em muitos centímetros, está toda salpicada de particulas de terra. Pode-se demonstrar, em áreas experimentais, que a intensidade da erosão é inversamente proporcional ao volume da matéria verde dos prados.

O solo fica modificado em seu equilíbrio pelo cultivo. As condições microclimáticas às quais está exposto são totalmente diferentes. Mal coberto por uma vegetação demasiado clara, se aquece e se esfria mais, e se resseca antes. Isto implica importantes modificações ecológicas para toda a sua fauna, de consequências todavia mal conhecidas. A vegetação natural proporciona-lhe uma camada abundante, porosa como uma esponja, que facilita a infiltração da água e o protege contra o efeito cinético, amortecendo as gotas caídas das árvores. O cultivo que explora as plantas não forma camada protetora no campo. O humus, abundante no solo natural, se rarifica. Ora, é ele quem, modificando a argila, cimenta com ela as partículas de solo em agregados mais resistentes aos choques que as próprias partículas. Graças a estes agregados, o solo é, a um só tempo, poroso, permeável e resistente à erosão pluvial. Os efeitos das correntezas ficam tão mais limitados quanto melhor os agregados estão formados e mais estáveis sejam. Ocorre que a exportação de matéria vegetal, que é o fim em si dos cultivos agrícolas, compromete a renovação do húmus, principal obstáculo à erosão do solo. A agricultura implica, portanto, em si, intrinsecamente, um risco de degradação dos solos que aumenta a suscetibilidade aos fenômenos morfogenéticos, enxurradas ou deflação eólica. Sucede a mesma coisa com os pastos: a cobertura vegetal se faz mais escassa, compromete-se a estrutura do solo e o pisoteamento da terra pelas patas dos animais facilita o arrastamento pelas águas.

\section{Adaptação empírica das civilizações camponesas}

A ação destes dois fatores da erosão agrícola, modificações na cobertura vegetal e mudança das condições da edafogênese, varia naturalmente segundo os tipos de 
cultivo e zonas climáticas. Todas as velhas civilizações agrícolas estiveram obrigadas a fazer frente empiricamente ao problema e só puderam subsistir as que o resolveram com um mínimo de eficácia. Por exemplo, a agricultura tradicional africana diminue as modificações do microclima dos solos e os efeitos da erosão pluvial deixando de substituir amplamente o dossel das grandes árvores do bosque com suas rotações. Por outro lado, a mistura de espécies diferentes no mesmo campo de cultivos, permitida pelas condições climáticas excepcionalmente favoráveis, diminue também os riscos de erosão pluvial. A alternância dos cultivos durante dois ou três anos e um retorno ao bosque durante quinze ou vinte permite ao solo reconstituir sua estrutura. Por fim, os trabalhos de cultivo, reduzidos ao mínimo, no geral um simples enterramento da planta, permitem evitar a exposição à intempérie de um solo demasiado esmiuçado, pouco resistente às violentas tempestades tropicais. Todas estas práticas são o fruto de um empirismo que permitiu subsistir, há milênios, povoados de cultivadores que dispõem de poucos meios técnicos e explotam um meio físico geográfico particularmente frágil. Não se pode fazer alterações sem grandes riscos num conjunto coerente e fortemente integrado também a toda uma série de fatos sociais e econômicos que pertencem à geografia humana. Algumas experiências desastrosas podem demonstrar-nos o que foi dito, como os milhões de libras esterlinas perdidas pelos ingleses na África oriental em uma tentativa de produção em massa de amendoim. Outras civilizações tão pouco souberam encontrar tal equilíbrio. É o caso dos cultivadores chineses de arroz. Antes de colocar no ponto as técnicas do cultivo irrigado, praticaram a exploração das vertentes utilizando as queimadas e os cultivos temporários para plantar o arroz. Provavelmente sob o efeito de uma rotação demasiado rápida das roças, as terras foram se degradando rapidamente e varridas pela erosão. As bases de sua civilização tradicional foram destruídas desse modo. Afortunadamente, isto se produziu quando esse povo havia começado já a praticar o cultivo do arroz inundado nas planícies aluvionais. O campesinato havia abandonado as vertentes, peladas e descarnadas, pelas regiões baixas nas quais o limo se acumula. Atualmente, em toda a China do Sul, as colinas são pouco menos que improdutivas enquanto que os homens se amontoam nas áreas dos arrozais inundados. Esta situação é o resultado de uma conversão agrícola total, efetuada no albor da história. Outros povos da Ásia do Sudeste, que não o fizeram, continuam vivendo do cultivo "itinerante" (em amplas clareiras florestais irregulares) do arroz de montanha nas regiões acidentadas. No podem passar de uma débil densidade de população e em relação aos cultivos ficaram muito atrasados com respeito aos demais.

Porém nem todos os povos tiveram êxito ao superar tal transtorno de sua civilização agrária. Isto é o que ocorreu, por exemplo, com os maias da América Central. A planta que haviam adotado, o milho, é uma das mais perigosas do ponto de vista da erosão, porque protege mal o solo e o deixa inteiramente desnudado nas primeiras borrascas da estação chuvosa, as mais violentas e perigosas. Por outra parte, o clima das regiões que ocuparam é particularmente agressivo, com chuvas muito intensas. Atualmente, um proceso erosivo excepcionalmente grande fez estragos nos campos 
de milho das regiões montanhosas da Guatemala, cunha dessa civilização. Em poucos decênios os solos foram arruinados e o milho, cada vez mais escasso, cede lugar a pastos miseráveis, terrenos baldios que ocultam seu verdadeiro nome. Preferindo por razões sanitárias as regiões montanhosas, os maias gastaram rapidamente as terras que exploraram. Daí toda uma história de migrações impostas pela busca de terras novas, o que provocou o abandono de brilhantes capitais e impediu a formação de um quadro territorial fixo.

Vê-se, por conseguinte, o papel primordial que representaram as tentativas mais ou menos coroadas de êxito de humildes camponeses na criação de condições alimentícias que proporcionaram às civilizações as bases do seu desenvolvimento. Os sistemas assim criados constituem conjuntos dotados de uma forte coesão, tanto do ponto de vista técnico quanto sociais e econômicos que formam o contexto da sua geografia humana. Sua modificação em função de um novo contexto é, pois, delicada. Examinemos alguns aspectos.

\section{Os elementos geomorfológicos da ordenação rural nos velhos países agrícolas}

O equilíbrio empírico realizado pelas civilizações rurais tradicionais é muito precário. Basta um fato insignificante para rompê-lo, e muitas das crises que as ameaça se produziram no passado. Sua análise pode contribuir poderosamente para esclarecer o presente, porque a racionalidade teórica deixa quase sempre de lado os fatores importantes quando aborda problemas tão complexos. Tal é a razão do interesse que representam os trabalhos do tipo dos de nosso discípulo J. Vogt.

J. Vogt estabeleceu a existência de uma crise de morfogênese agrícola nas regiões situadas entre a bacia de Paris e da Boêmia durante um período que varia, segundo os casos, entre meados do século XVIII e do século XIX. Suas origens são, a um só tempo, um notável progresso demográfico e os primeiros elementos do capitalismo, incitando os grandes proprietários a extrair da terra um proveito crescente. Como os métodos da "revolução agrícola" se encontram todavia ainda em gestação, fatiga-se a terra querendo-se fazer que produza mais. Efetuam-se rotações até o limite do possível. Nas montanhas pobres onde se pratica o arroteio, as queimadas se produzem a um ritmo cada vez maior e se efetua em ladeiras demasiado enclinadas. Desencadeia-se assim uma violenta erosão que adquire características particularmente catastróficas nos anos de invernos inclementes ou nevados. Massas de terra são assim arrastadas e as rochas vêm à superfície do solo: "as pedras crescem", dizem os camponeses. Nas áreas arenosas dos Vosges, consideráveis massas de areia são arrastadas para o fundo dos vales e cobrem os prados fertéis, inclusive algumas áreas de cultivo situadas aos pés das vertentes. Colmatam-se os tanques protegidos por obras de serralheria. Em resumo, uma verdadeira catástrofe regional abate-se ná segunda metade do século XVIII e acaba por desencadear uma emigração em massa, 
favorecida pelos conflitos de fins de século e pela independência americana. Este exemplo tem um valor geral. Encontramo-lo em numerosas regiões da África e do Brasil onde o aumento demográfico atual provoca o cultivo, por queimadas, em vertentes que se erosionam, e acumulam massas de areia estéril nas depressões que podiam ser transformadas em arrozais se o progresso técnico houvesse avançado a par com a multiplicação dos homens.

Nas mesetas de calcário da Lorena, o mesmo período se traduz por uma rotação de culturas obrigatória antes de sua supressão legal pela Revolução. Importantes massas de cultivo de uma mesma planta, lavradas ao mesmo tempo, constituem um perigo crescente. De fato, oferecem condições homogêneas à morfogênese. A concentração de certas áreas em grandes parcelas de propriedades burguesas leva ao mesmo resultado. Os efeitos foram mais graves dado que uma criação de gado insuficiente proporcionava esterco em quantidade escassa para conservar a estrutura dos solos, e estes se faziam cada vez mais sensíveis aos efeitos da passagem das águas. Por último, a necessidade de se obter a todo custo colheitas de primavera aumentou ainda mais o perigo, deixando o solo desnudo no período crítico do degelo. As primeiras plantas de capina, como a batata, mal protetoras do solo, contribuíram também para o desencadeamento da crise. Esta alcançou seu grau máximo às vésperas da Revolução, acentuando as rivalidades sociais, e desempenhou seu papel no desenvolvimento dos acontecimentos políticos. Traduziu-se em graves devastações nas zonas deixadas às intempéries, onde massas de terras se despencaram pelas vertentes, produzindo o descarnamento geral da superfície do solo sob o efeito das enxurradas difusas. Em consequência desta crise, muitas terras foram abandonadas. Tudo termina com o desenvolvimento do cultivo do trevo e da alfafa que melhora os solos e permite beneficiá-los com estercos, a rotação de culturas, e o desenvolvimento do individualismo agrário, que faz alternar as diferentes culturas nas encostas ao azar dos desejos e das possibilidades de cada agricultor.

Em nossos dias, a urgente modernização da agricultura coloca problemas que as crises do século XVIII nos ajudam a compreender. Isto exige um aumento dos rendimentos que implica recorrer de um modo geral aos fertilizantes químicos. Porém, estes não contribuem para a conservação da estrutura do solo e os reguladores químicos, sobretudo os produtos norte-americanos, que têm um preço geralmente proibitivo e eficácia insuficiente. É preciso, portanto, adubar as terras para fazê-las mais resistentes, tanto mais que a erosão, ao arrastar os adubos, provoca perdas importantes para o agricultor, inclusive a curto prazo. Os progressos técnicos permitem facilmente o uso de adubos artificiais. Porém seu emprego requer forçosamente um gasto que muitos orçamentos camponeses podem suportar com dificuldade. Seria vantajoso, por conseguinte, ter em conta os riscos da erosão, como os que resultam conjuntamente das características dos solos e das condições geomorfológicas, para aconselhar sua aplicação. Efetivamente, ali onde as enxurradas correm maior risco de desencadear-se, impõe-se mais recorrer aos estercos orgânicos, independentemente de seu efeito direto sobre os rendimentos, que é tema dos agrônomos. 
A modernização de nossa agricultura exige recorrer de um modo crescente à ajuda das máquinas, o que impõe uma nova modelação da gleba. Isso coloca o problema das sebes de proteção. Na França, a lei de 1942 inspirou-se unicamente no espírito da geometria que Pascal opunha tão justamente ao espírito da finura. Toma em consideração o reagrupamento ou concentração das parcelas em superfícies tão grandes quanto seja possível, sem preocupar-se com o meio geográfico no qual se efetua o cultivo. Não exige estudo edafológico prévio, nem considera nenhum dos efeitos que a remodelação possa ter sobre a erosão. No entanto, estes são consideráveis. A destruição dos taludes na Bretanha se traduz em uma ação crescente do vento que frequentemente desencadeia, nas terras leves e de má estrutura, fenômenos de deflação eólea com levantamento de pó. Não quer isto dizer que defendamos a manutenção das sebes de bosques. Muitas são inúteis e interferem no trabalho mecanizado. Porém antes de descartá-las, não seria demais considerar sua utilidade e não fazer de aprendizes de bruxo. Têm sua razão de ser, inclusive quando, perdendo sua finalidade original, foram excessivamente multiplicadas. Em certos países de campos abertos, criam-se, a grandes custos, cortinas de árvores que são uma grande tela de cobertura adaptadas à agricultura moderna. Se isto se faz simultaneamente na pradaria norte-americana, nas planícies da Hungria, nas estepes da Rússia e da Ucrânia e nas colinas das grandes planícies morânicas da Alemanha democrática, não é por certo o resultado de uma aberração coletiva. Sabe-se que as telas vegetais de proteção permitem às plantas resistir melhor aos ventos abrasadores e favorecem à conservação dos solos. Apesar das diferenças de clima, uma parte dos resultados pode ser aplicada também na França. Haveria que determinar exatamente, pelas estações agronômicas, em que medida e de que maneira, tendo em conta nossas plantas, nossos solos e nossos climas. Uma vez estabelecidos esses resultados ecológicos, seria conveniente, por meio de estudos de terras, relacionando microclimatologia, edafologia e geomorfologia, determinar que sebes úteis haverá que conservar para o bem geral e mantê-las. Deverão constituir um dos quadros de uma reconstituição racional, numa verdadeira remodelação das glebas. Por exemplo, em uma vertente ao amparo dos ventos dominantes, pode-se certamente suprimir a maior parte das sebes sem resultados nefastos. Em troca, em uma vertente frontal ao vento, que a nada protege, e sobretudo em sua parte superior, é preciso conservar uma quadrícula de malhas mais apertadas. $\mathrm{O}$ mesmo ocorre com as zonas de colinas.

\section{A regeneração de terrenos e a erosão}

Nas regiões de campos abertos, a regeneração coloca graves problemas geomorfológicos. Conduz, como no século XVIII, a formar grandes parcelas de um só aspecto que se ocupam inteiramente com o mesmo cultivo. Se o solo é plano ou com escassa pendente, deve-se ter em conta suas próprias características, para permitir um apreciável escoamento das água. Isto não representa nenhum perigo. Porém 
se o relevo é acidentado, as coisas sucedem de outro modo e a erosão se desencadeia tanto mais facilmente quanto mais ativo é o clima. Uma chuva abundante ou uma fusão de neve pode provocar uma catástrofe. Os sulcos produzidos pelas águas são dissolvidos facilmente pelo trator e os danos geomorfológicos não são os mais graves. Porém alguma camada de solo fértil sempre é arrastada. Toda inversão em trabalho e adubagem que o campesinato tinha incorporado ao solo se perde e pode ter como consequência uma duradoura baixa de rendimento. As mesmas colheitas só serão obtidas graças a doses de fertilizantes ampliadas. Em geral, não se tem em conta o cálculo de tais perdas. É um erro. Representam muito no balanço de uma agricultura. Na União Soviética o desenvolvimento do cultivo mecanizado, permitido pela socialização e pela regeneração dos solos cultivados não proporciona só vantagens. Em certos colsoses e solcoses os rendimentos têm diminuido catastroficamente por conta de um enorme processo de erosão. Preconizam-se medidas para contê-la, porém com frequência depois da mecanização e dos danos provocados. Cortam-se sobretudo as ladeiras fazendo-as em faixas, traçadas geralmente nas curvas de nível, dedicadas umas ao trabalho agrícola e outras ao capim e árvores frutíferas. Desse modo, freia-se as enxurradas e a erosão não chega a concentrar-se num ponto. As faixas de grama desempenham o papel de pente, os produtos arrastados se depositam nelas e vêm a fertilizá-las: não se tem perda de todo. Todavia, progressivamente, o solo, limpado aqui e esgotado acolá, acabará igual aos terraços característicos de alguns de nossos campos. Também nos Estados Unidos cortam-se em degraus as encostas que sofrem erosão.

Por conseguinte, uma verdadeira recuperação de terras deveria vir acompanhada de um remodelado dos terrenos que contribuisse para estabilizá-los frente à erosão agrícola e permitisse evitar que as vantagens adquiridas por um lado sejam contrarrestadas polos inconvenientes surgidos de outro. Por exemplo, nas encostas da Gasconha, o desenvolvimento do cultivo do milho, muito rápido, acentúa consideravelmente a erosão, porque esta planta é uma das mais perigosas deste ponto de vista. Seria conveniente localizá-la ali onde o risco de erosão fosse mais débil, sobretudo no fundo dos vales, o que implica o seu saneamento. Haveria que reservar as vertentes, sobretudo as que são mais inclinadas, para pastos ou campos artificiais, cujo rendimento não será satisfatório senão com irrigação complementar. Em muitas regiões de colinas, dedicadas ao policultivo, haverá que adaptar-se o desenho das parcelas recuperadas às exigências da luta contra a erosão, adaptando-as paralelamente às curvas de nível nas vertentes, limitando sua largura e separando-as às vezes com franjas de hortas. Os campos devem localizar-se onde a passagem das águas for demasiado forte sobre a terra lavrada e provoque o arrasto de superfície.

Não alimentamos ilusão e sabemos muito bem que tal remodelagem das terras chocará com grandes resistências, tanto como a recuperação. Porém, não far-se-á? Além do mais, essa necessária remodelagem de muitas de nossas áreas agrícolas está relacionada com uma evolução econômica na qual o Tratado de Roma deve desempenhar um importante papel e não se fará em poucos meses. Exige também 
uma séria preparação se não se quer desacreditar em realizações apressadas uma ação de longo alcance. É preciso, portanto, reunir desde agora os dados básicos associando estreitamente edafólogos, agrônomos e geógrafos em um trabalho de equipe.

No que se refere à geomorfologia, as investigações preparatórias consistirão em duas séries de estudo:

- Uma análise mais detalhada dos processos da morfogenese agrícola por meio de medidas sobre o terreno para os quais haverá que inspirar-se nos métodos estabelecidos por C. Rougerie. Há que medir as caudais que percorrem as terras cultivadas em diversas circunstâncias meteorológicas e compará-los com as condições dos solos, do relevo e das culturas diferentes afim de determinar a superfície-limite do escoamento concentrado e precisar as modalidades do escoamento difuso. A superficie-limite do escoamento concentrado permitirá fixar um tamanho limite às parcelas, porque em nenhum caso deve ultrapassálo uma parcela de cultivo. Efetuar-se-ão também tomadas de amostras da água para estabelecer a natureza dos diversos materiais dissolvidos nela e suas porcentagens. Avaliar-se-á igualmente os transportes de limo e argila em suspensão. Todas estas medidas serão tomadas em campo, em bacias de algumas centenas de hectares e, por conseguinte, a uma escala que permita transportar ao âmbito geral da natureza os resultados obtidos nas parcelas experimentais cuja superfície não passe, em geral, de uma centena de metros quadrados;

- Levantamento cartográfico detalhado das terras a escalas cadastrais (1/1000 a 1/15000), concebidos segundo o princípio dos mapas geomorfológicos porém com um fundo edafológico. Poder-se-á utilizar sobretudo mapas geoedafológicos da A. Journaux. Representar-se-á neles todos os fenômenos que interessam ao meio agrícola: zonas de inundação, de escoamento difuso, de escoamento concentrado mais ou menos frequente, os fenômenos de arrasto de superfície do solo, de voçorocas abertas ou não pelos cultivos, de solifluxão, etc. Frequentemente o arrasto de superfície dos solos será apreciado unindo a observação geomorfológica e a análise edafológica porque esta última permite, nos solos de horizontes mal diferenciados, reconhecer a profundidade inicial de horizontes que se encontram atualmente em afloramento. Igual interesse se concederá aos fenômenos de acumulação e coluvionamento e aos solos enterrados. Edafólogo e geomorfólogo estarão estreitamente relacionados nessa cartografia, o que responde às exigências do remodelado da terra, que não se pode conceber sem uma sólida base edafológica.

Para tais estudos podemos usar da experiência adquirida no exterior. Na Alemanha Federal se efetuou investigações desse gênero. Também se fez na França alguns ensaios que pelo menos permitem assimilar alguns problemas de método. Seria fácil desenvolver tais investigações e situá-las, em alguns anos, ao nível da aplicação sistemática. Os gastos necessários seriam supreendentemente modestos com relação às exigências da maior parte dos ramos científicos. 


\section{A Geomorfologia e a colonização agrícola}

Os problemas que se colocam ao valorar do ponto de vista agrícola regiões pouco ou nada exploradas são sensivelmente diferentes. Não se trata de paliar os riscos que uma modificação em um sistema existente fará aparecer, mas de impedir as consequências verdadeiramente desastrosas que possam trazer um transtorno completo do equilíbrio natural.

\section{Experiências desastrosas}

Temos certo número de exemplos para demonstrar que esses riscos são bem reais e de temível amplitude. A este respeito pode-se falar da agricultura mineira ou de Raubwirtschaft. Com efeito, em algumas colheitas dilapida-se o capital edafológico constituído pela terra e logo esta é abandonada em estado que já não resta opção para cultivá-la de novo.

Foi com frequência o caso dos Estados Unidos antes de criar-se, diante da evidência, um serviço de conservação dos solos, que é um dos modelos no gênero. A utilização do solo anteriormente fazia-se queimando-se as matas, lavrando-se nas encostas no sentido da declividade e repetindo-se anos após anos, sem esterco ou fertilizantes, o mesmo tipo de cultura. Sob um clima geralmente agressivo, os resultados foram lamentáveis. Em um século, perto de um quarto do espaço agrícola foi tão intensamente desgastado pela erosão que quase foi dado por perdido. A morfogênese alcançou uma enorme intensidade: abriram-se sulcos nas vertentes, escavaram-se barrancos de vários metros, enormes massas de sedimentos foram levadas para o fundo dos vales e embocaduras dos rios. Nunca os fenômenos naturais alcançaram tais proporções em tão pouco tempo. Em trinta anos, nas grandes planícies, os campos de trigo deram lugar a montes de dunas de vez que o vento levou para longe, sob a forma de tempestades de poeira (dust bowls), todos os elementos finos de um solo cujo monocultivo extensivo havia privado de estrutura. Os danos não se limitaram à agricultura: o abastecimento d'água esgotou-se porque diminuiu a alimentação das nascentes; as inundações se fizeram mais bruscas e maiores devido ao maior escoamento superficial das águas das chuvas; a navegação foi prejudicada pelo acúmulo dos sedimentos depositados no leitos dos rios; os litorais encheram-se de lama e foram abandonados pelos barcos. Em consequência, a mais rica região do mundo teve de entregar-se a um paciente esforço de recuperação, que, apesar da ajuda do Estado, não impediu uma crise agrícola permanente e a deserção dos habitantes do campo. O fazendeiro das terras erodidas já não se enriquece. Vive inclusive geralmente mal e contrasta com as novas regiões nascidas da irrigação a oeste.

No Brasil, entre os estado do Rio de Janeiro e de São Paulo, o espetáculo do vale do Paraíba do Sul é lamentável. Um semi-abandono rural sucedeu a uma rica produ- 
ção cafeeira que começou fazia um século. Destruiu-se barbaramente a cobertura florestal, a ferro e fogo, para plantar o café que, durante um certo tempo, substituiu as fabulosas minas de ouro do Estado de Minas Gerais. Os latossolos foram expostos aos agentes atmosféricos em pendentes de vinte a trinta graus. Aconteceu o que se temia. A erosão destruiu rapidamente os horizontes amarelos superficiais, os únicos que constituem um solo verdadeiro, e denudaram as camadas avermelhadas inferiores, estéreis. Ressecadas nas estiagens e endurecidas, oferecem nos períodos chuvosos um solo insuficientemente permeável. Começaram a formar-se voçorocas de vinte a trinta metros de espessura. O cultivo teve que ser abandonado e isto deu azo a imensos pastos pobres, salpicados de matagais, lacerados por desbarrancamentos, cortados pelas feridas abertas por grandes deslizamentos provocados pelas chuvas torrenciais. São necessários um a dois hectares para alimentar a um animal e uma população rural reduzida a uma densidade de cinco habitantes por quilômetro quadrado migrou rapidamente para o trabalho nas fábricas que se implantaram em ambas capitais. Trinta anos de agricultura mineral deram como resultado esta devastação, que, por desgraça, não é uma exceção no Brasil.

No mundo, por toda parte, a onda demográfica atual lança homens famintos à conquista de terras novas. Impulsionados pela necessidade, aferram-se eles à natureza usando dos meios mais primitivos. A colonização espontânea de certos distritos de Sumatra sobre queimadas veio a dar no cultivo das vertentes e a uma imensa crise de morfogênese antrópica. As possibilidades arrozeiras do fundo dos vales foram malbaratadas talvez irremediavelmente. Porém, como pedir a homens famintos, abandonados a si mesmos, a organização de arrozais de regadio, sobretudo numa época de sputniks e de experiências atômicas?

A gravidade do problema se mede em porcentagens de expansão demográfica. Já era hora de não deixar-se arruinar por umas poucas colheitas as terras cultiváveis de extensão limitada. Isto supõe, naturalmente, inversões, e esta questão supera em muito a geomorfologia e a edafologia. Estas, entretanto, estão implicadas no problema.

\section{Um exemplo alentador}

Com efeito, o cultivo de um território não explorado só deveria fazer-se depois que alguns estudos preliminares tivessem permitido determinar suas aptidões do tríplice ponto de vista geomorfológico, edafológico e ecológico. Um exemplo de utilização desse método nos dá o delta do Senegal. Nesta região, o problema era particularmente complexo porque tratava-se de implantar um sistema de irrigação. Os métodos empregados foram os básicos: análise detalhada dos processos e cartografia do substrato físico.

A análise dos processos permitiu determinar a origem do sal como o principal obstáculo ao cultivo. A maior parte provém da deflação eólica. O restante, vem da 
ascensão capilar depositada nas areias argilosas de certos áreas constituídas quando o delta atual formava um sistema de lagunas muito salgadas e uma parte insignificante de águas estuarinas que remontam aos braços do rio na estação seca foi alijada para algumas depressões quando da subida das águas. Sobre as formas de relevo dunquerquianas a vegetação reduz-se a algumas matas, o que permite ao vento estender pela superfície do delta a argila salgada que carrega. Um sistema de ordenamento beneficiava essas áreas de relevo geralmente insubmergíveis, para instalar nelas canais de distribuição da água, habitações, construções agrícolas, etc, permitindo bloquear a deflação eólica e aproveitando, para usos não agrícolas, as terras quase improdutivas. A inclinação contínua e regular dessas áreas presta-se perfeitamente para a instalação, com um gasto pequeno, de uma rede de distribuição d'água por gravidade. Outro aspecto importante da geodinâmica é o trabalho do próprio rio. O regime, com a alternância de uma elevação do volume d'água de uns seis mil metros cúbicos por segundo e de um período de estiagem no qual o escoamento quase cessa, permitindo às águas marinhas avançar sobre os braços principais, é o gerador de particularidades tais como os processos de erosão eólica. Nessas épocas produz-se um efeito de ação das águas particularmente intenso justamente antes dos transbordamentos, que provoca um rápido deslocamento dos bancos de areia e o socavamento intenso das margens. Formam-se meandros que evoluem então com relativa rapidez, e localizam-se frequentemente ali onde o leito atinge uma massa de areia de dunas quaternárias. Uma melhora das condições de navegação pode, entretanto, lograr-se atuando-se sobre pontos adequados.

Todos os aspectos da atual dinâmica, assim como as paleoformas herdadas de uma complexa evolução recente, marcada por alternâncias de períodos úmidos e períodos secos, foram representados em mapas geomorfológicos de 1/50.000 que levantamos. Fizemos constar também a natureza litológica das formações em afloramento. Indicou-se a idade de cada tipo de solo, o que permite determinar-se a existência de paleosolos, sobretudo de solos característicos das dunas antigas e devidas a um clima mais úmico que o nosso. O mapa serviu de ponto de partida, com levantamentos edafológicos e geobotânicos (que dão uma visão sintética dos meios ecológicos), para o estabelecimento de planos de ordenamento do delta, sobretudo para o projeto de represamento do Dagana. Graças a isso, foi possível delimitar as regiões, para as quais foram feitos levantamentos topográficos detalhados. Com efeito, tendo-se a disposição dos depósitos aluvionais, as bacias de depositação, os pequenos deltas de ruptura dos depósitos atuais e antigos, pôde-se fazer uma idéia mais precisas das diferenças de altitude entre as unidades geomorfológicas situadas uma ao lado das outras e traçar as grandes linhas de um plano de ordenamento. Os levantamentos topográficos precisos, que são trabalhosos, foram limitados a perfis e itinerários escolhidos em função de dados proporcionados pelo mapa geomorfológico. Graças a isto, foi possível determinar uma política de ordenamento que tem em conta a dinâmica natural. Por exemplo, foi descartado um projeto de represa em Guina, rio acima, que reteria as águas no começo das cheias para soltá-las abruptamente 
com a intenção de diminuir as perdas por evaporação e provocar uma submersão mais rápida. $\mathrm{O}$ projeto tinha como principal inconveniente acentuar a migração dos meandros que dificultava a navegação, e não evitar o perigo de congestionar os canais e ameaçar várias aglomerações urbanas. Decidiu-se por preferir a represa do Dagana, menos cara e sem inconvenientes. Fez-se igualmente grande economia, que alcançam $30 \%$ dos trabalhos de escavação, adaptando-se o traçado dos canais e a disposição dos canteiros de arroz aos dados geomorfológicos, no lugar de adotar uma configuração mais geométrica como o que se fazia antes. Certas elevações aluvionais, reforçadas em determinados pontos, podem proporcionar excelentes diques sobre os quais correm caminhos usados para transporte. Os emissários de algumas bacias, retificados e escavados de novo, foram aproveitados para escoamento e as próprias bacias se transformaram em áreas de plantio de arroz. Nos arredores de Rosso há cinco mil hectares de arrozais ordenados diretamente em função do mapa geomorfológico.

O êxito obtido nesta ocasião fez que o Centro de Geografia Aplicada tenha sido convidado para estudar os problemas geomorfológico-edafológicos postos para o ordenamento do vale do Niger e para diversas bacias fluviais do Brasil. Em Mali, nossos trabalhos permitiram modificar fundamentalmente certos programas de valorização, sobretudo na região de Gundam. Posteriores comprovações demonstraram o grande interesse de tais investigações aos consideráveis riscos de fracasso que podem evitar.

O estudo das bases físicas sistemático dos problemas agrícolas, quer se trate de regiões antigamente cultivadas que se quer mudar, ou de países novos, é igualmente indispensável. A Edafologia e a Agronomia fornecem importante apoio e proporcionam dados originais sobre o comportamento e a natureza sobre a qual trabalha o agricultor. É possível precisar a natureza e medir a importância da Geomorfologia. Seu lugar, na relação com a Agronomia, é um pouco parecido ao da Fisiologia com a Medicina. Sua intervenção pode revestir formas múltiplas adaptando-se a todas as situações. Apreciando a extensão dos danos que causa ao meio ambiente uma exploração agrícola mal conduzida, pode sugerir soluções variadas. Não há que esquecer que a rotação de culturas impõe ao equilíbrio natural um verdadeiro traumatismo cujos efeitos importa limitar. O ordenamento em terraços em vertentes pode efetuarse tão bem com o bulldozer nos países industrializados como com o trabalho do homem nos países que dispõem de excedentes de mão a empregar. Com frequência, o recurso do emprego da intervenção humana é a solução para os países pobres em capital e premidos pela fome. $\mathrm{O}$ bom conhecimento das bases físicas permite fazer esse uso com a máxima utilidade. Em 1954 preconizamos uma política de restauração dos solos do Futa Dialon. Havia-se recorrido unicamente ao uso da mão-deobra, muito abundante em certas estações, sob a forma da murada de pedras cortando as vertentes cultivadas e impedindo seu desmoronamento. Em muitas regiões tais inversões são urgentes e as massas de trabalhadores com poucas oportunidades de emprego as aguardam com impaciência. 
Nossos conhecimentos ajudarão a estabelecer o programa adaptando-o às exigências naturais, do mesmo modo como deve representar seu papel num novo modelado das terras dos velhos países agrícolas industrializados nos quais é necessário elevar a produtividade da terra ao nível da indústria, sem destruí-la, ou na preparação dos grandes equipamentos próprios para permitir novas colheitas em vastas extensões de áreas mal aproveitadas. Nas crises agrícolas mundiais, eles acodem oportunamente, e é urgente pedi-los, junto a outros tantos campos científicos, a todos que possam prestar serviços se se quer que nossos filhos possam comer o que precisam. 